Chemical Technology Division

\title{
Lewis-Acid/Base Effects on Gallium Volatility in Molten Chlorides
}

\author{
D. F. Williams \\ G. D. Del Cul \\ L. M. Toth* \\ E. D. Collins
}

*Consulting Chemist, Electrochemical Systems, Inc., Knoxville TN

Date Published—February 2001

Prepared for the

Fissile Materials Disposition Program

\author{
Prepared by the \\ OAK RIDGE NATIONAL LABORATORY \\ Oak Ridge, Tennessee 37831-6285 \\ managed by \\ UT-BATTELLE, LLC \\ for the \\ U.S. DEPARTMENT OF ENERGY \\ under contract DE-AC05-00OR22725
}




\section{CONTENTS}

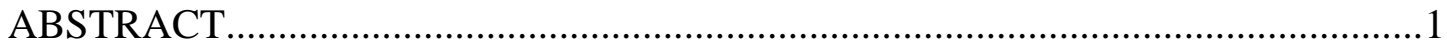

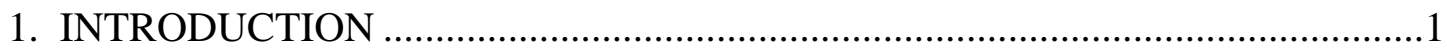

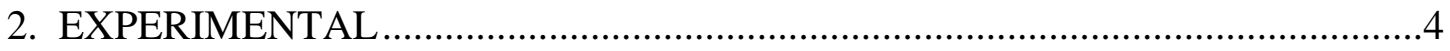

3. RESULTS AND RECOMMENDATIONS .....................................................

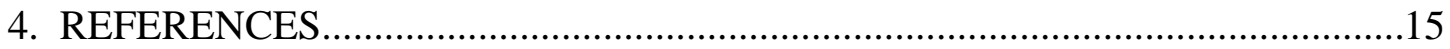

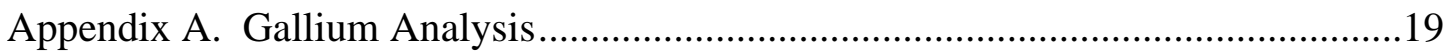

Appendix B. Coordination Numbers for Selected Cations ......................................23 


\section{LIST OF TABLES}

$\underline{\text { Table }}$

$\underline{\text { Page }}$

$1 \quad$ Reagents used in gallium volatility trials .............................................

2 Estimate of free chloride content of the AIDA/MOX salt................................10

3 Estimates of free chloride contents of experimental salt mixtures ...................11

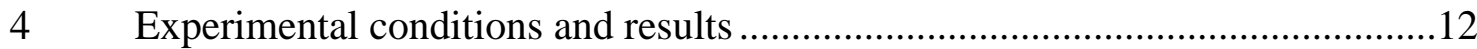




\section{LIST OF FIGURES}

$\underline{\text { Figure }}$

$\underline{\text { Page }}$

$1 \quad$ Variation of aluminum volatility with Lewis-acid character .............................

$2 \quad$ First apparatus used for gallium volatility trials .......................................5

3 Second apparatus used for gallium volatility trials ........................................6

$4 \quad$ Temperature and flow history for trial 2

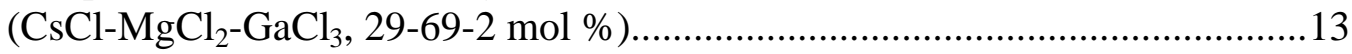

$5 \quad$ Temperature and flow history for trial 3

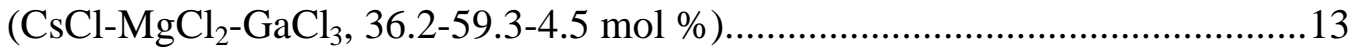

6 Temperature and flow history for trial 4

( $\left.\mathrm{NaCl}-\mathrm{KCl}-\mathrm{CeCl}_{3}-\mathrm{GaCl}_{3}, 24.7-24.5-48.5-2.3 \mathrm{~mol} \%\right)$.....................................14 


\title{
Lewis-Acid/Base Effects on Gallium Volatility in Molten Chlorides
}

\author{
D. F. Williams, G. D. Del Cul, L. M. Toth, E. D. Collins
}

\begin{abstract}
It has been proposed that $\mathrm{GaCl}_{3}$ can be removed by direct volatilization from a $\mathrm{Pu}-\mathrm{Ga}$ alloy that is dissolved in a molten chloride salt. Although pure $\mathrm{GaCl}_{3}$ is quite volatile (boiling point, $201^{\circ} \mathrm{C}$ ), the behavior of $\mathrm{GaCl}_{3}$ dissolved in chloride salts is different due to solution effects and is critically dependent on the composition of the solvent salt (i.e., its Lewis-acid/base character). In this report, the behavior of gallium in prototypical Lewis-acid and Lewis-base salts is compared. It was found that gallium volatility is suppressed in basic melts and enhanced in acidic melts. The implications of these results on the potential for simple gallium removal in molten salt systems are significant.
\end{abstract}

\section{INTRODUCTION}

The primary purification needed to convert weapons-grade plutonium from a metal to an oxide fuel is the removal of up to $5 \mathrm{wt} \%$ gallium from the alloy. In conventional aqueous purification schemes, gallium is readily and completely removed by solvent extraction [1]. For molten salt-based conversion of metal to oxide, the removal of gallium as a volatile species $\left(\mathrm{GaCl}_{3}\right)$ has been proposed as the treatment necessary before fabrication of VIPAC MOX fuel [2]. The removal of volatile gallium takes place after the weapons alloy has been dissolved in a chloride salt by reaction with chlorine gas. This report covers some preliminary experiments that indicate that the volatility of gallium dissolved in a chloride salt is largely governed by the Lewis-acid character of the salt.

Because the Lewis-acid/base character of salt mixtures is unfamiliar to many, the following brief background is provided. Salt mixtures that are Lewis bases have an abundance of uncomplexed anions that are available to stabilize certain metal ions by forming coordination complexes that exhibit a reduced volatility. Lewis bases tend to be 
rich in monovalent cations with a low coordination number (i.e., alkali metal cations). In a formal sense, these salts are basic because of the excess of uncomplexed anions, $\mathrm{X}^{-}$, that act as electron-donating species. Salt mixtures that are Lewis acids, on the other hand, have most of the anions already localized in coordination complexes; therefore, no "free" anions exist to further stabilize metal ions in solution. Thus, higher thermodynamic activity coefficients are observed for these metal ions in acidic media, which results in increased reactivity and volatility for these species. Lewis acids are rich in cations for which the coordination demand exceeds the oxidation state (i.e., transition metals, rare earths, and actinides).

The importance of the Lewis-acid character of halide salts has been known, but not widely recognized, for many years. This importance was most evident during the development of molten fluorides as fluid fuels and for volatility processing [3]. However, the removal of gallium from molten chlorides is most closely related to systems studied by the aluminum industry. The chemistry of aluminum is very similar to that of gallium and serves as an excellent predictor of gallium behavior in molten chlorides. Figure 1 illustrates the dramatic effect of increased Lewis acidity on the volatility of aluminum species in the $\mathrm{NaCl}-\mathrm{AlCl}_{3}$ system. As the aluminum chloride content of the salt increases, the free chloride content decreases, the Lewis acidity increases, and the volatility rapidly increases as the balance of species shifts from basic to acidic $[4,5]$. The nature of the volatile species also changes. In basic media, the lessvolatile adduct $\left(\mathrm{NaAlCl}_{4}\right)$ predominates, while in acidic media, the highly volatile $\mathrm{AlCl}_{3}$ is collected in the gas phase. The Lewis-acid measure used in Fig. 1, a simplified estimate of the free chloride content of the salt, was calculated as follows:

$$
\sum_{\text {cations }}(\text { oxidation state - coordination demand }) \cdot \operatorname{mol} \%
$$

For sodium and aluminum, the oxidation states are 1 and 3, respectively, and their respective coordination demands are estimated to be 0 and 4 . For more complicated systems, the competition for anions is a function of all components present and the particular affinities that exist for forming all potential complexes. 


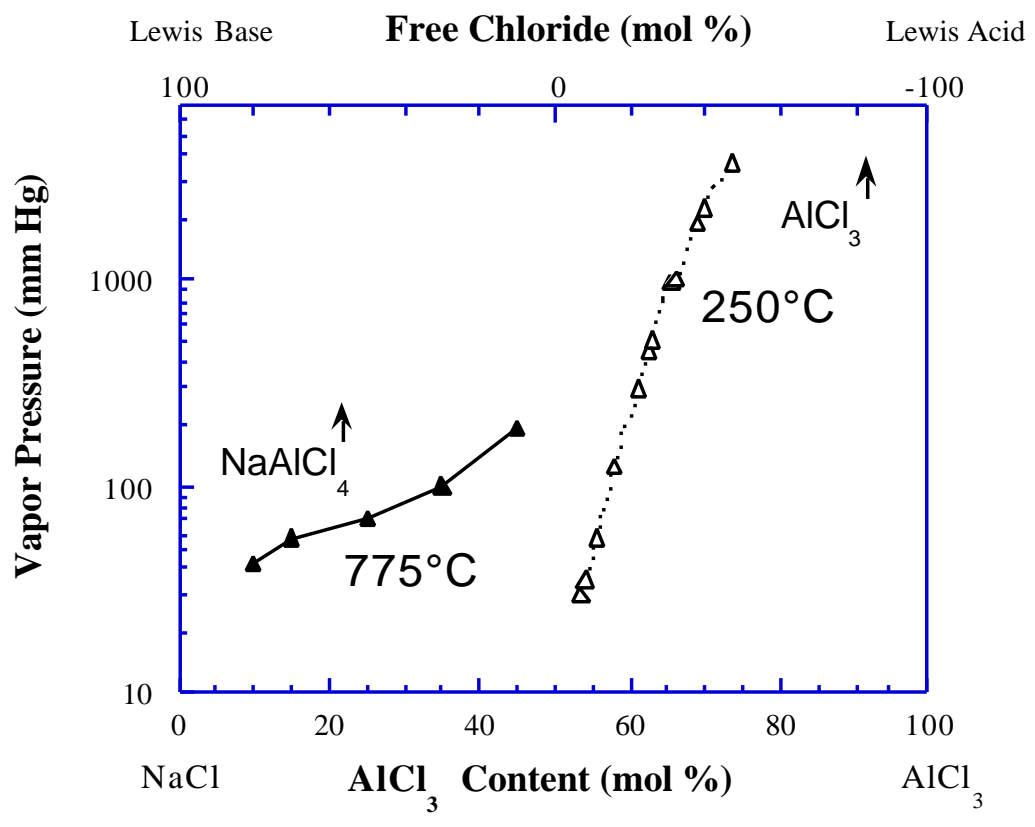

Fig. 1. Variation of aluminum volatility with Lewis-acid character $[4,5]$. 


\section{EXPERIMENTAL}

The chemicals used in this study (see Table 1) were greater than $99.9 \%$ in purity. All salts and metals were ultradry and supplied in ultradry packaging (ampouled under argon). With the exception of $\mathrm{GaCl}_{3}$, gallium metal, and cerium metal, the solid reagents were also dried overnight at $200^{\circ} \mathrm{C}$ under high vacuum before use. All reagents were handled exclusively in an inert-atmosphere chamber prior to and during the assembly of the experimental apparatus. Gases used in this work were of the highest purity available.

Table 1. Reagents used in gallium volatility trials

\begin{tabular}{|c|c|c|c|}
\hline & Reagent & Minimum purity $(\%)$ & Source \\
\hline \multicolumn{4}{|c|}{ Salts } \\
\hline & $\mathrm{NaCl}$ & 99.99 & Alfa-Aesar \# 35716 \\
\hline & $\mathrm{KCl}$ & 99.95 & Alfa-Aesar \# 14466 \\
\hline & $\mathrm{CsCl}$ & 99.9 & Alfa-Aesar \# 42832 \\
\hline & $\mathrm{MgCl}_{2}$ & 99.99 & Alfa-Aesar \# 42850 \\
\hline & $\mathrm{CeCl}_{3}$ & 99.9 & Alfa-Aesar \# 35688 \\
\hline & $\mathrm{GaCl}_{3}$ & 99.999 & Alfa-Aesar \# 11867 \\
\hline \multicolumn{4}{|c|}{ Metals } \\
\hline & Gallium & 99.9999 & Alfa-Aesar \# 42872 \\
\hline & Cerium & 99.9 & Alfa-Aesar \# 40025 \\
\hline \multicolumn{4}{|c|}{ Gases } \\
\hline & Helium & $\begin{array}{l}99.998 \\
\left(<2 \mathrm{ppm} \mathrm{H}_{2} \mathrm{O}\right)\end{array}$ & $\begin{array}{l}\text { Air Liquide } \\
\text { (UHP Grade) }\end{array}$ \\
\hline & Chlorine & $\begin{array}{l}99.998 \\
\left(<2 \mathrm{ppm} \mathrm{H}_{2} \mathrm{O}\right)\end{array}$ & $\begin{array}{l}\text { Air Products } \\
\text { (VLSI Grade) }\end{array}$ \\
\hline
\end{tabular}

Two types of apparatus were used for the experiments. The first type, which was of quartz and glass construction, was used for the early trials that utilized gallium in the form of $\mathrm{GaCl}_{3}$ and helium sparging. The second type of apparatus included a glassy carbon crucible for metal dissolution and gallium volatilization by chlorine sparging. The first type of apparatus is shown in Fig. 2. It consists of a laboratory furnace and a gas-tight reaction chamber that is connected to appropriate supply and off-gas piping. The 23-mm-ID x 15-in.-long fused-silica reaction tube is connected to an O-ring sealed 
plenum. With the exception of the sparge-tube slip seal, all connections were made with Cajon VCO fittings, and the gas-tight sliding seal for the 4-mm-OD silica sparge tube was made with a custom teflon ferrule located outside the heated zone. In these preliminary tests, no attempt was made to heat-trace the chamber plenum and off-gas piping because we wanted to observe the upper reaction tube and plenum during the experiment. Thus, the cold portion of the reaction tube and plenum acted as condensing surfaces for $\mathrm{GaCl}_{3}$, and the cold trap and aqueous exhaust bubbler served as the final trapping agents for condensable or reactive gases. The silica reaction tube was sectioned after the trial to provide representative specimens for leaching/dissolution and chemical analysis. Gas flow was controlled by manual adjustment and verified by wet-test meter measurements. The chamber temperature was indicated by thermocouples and regulated by a furnace controller.

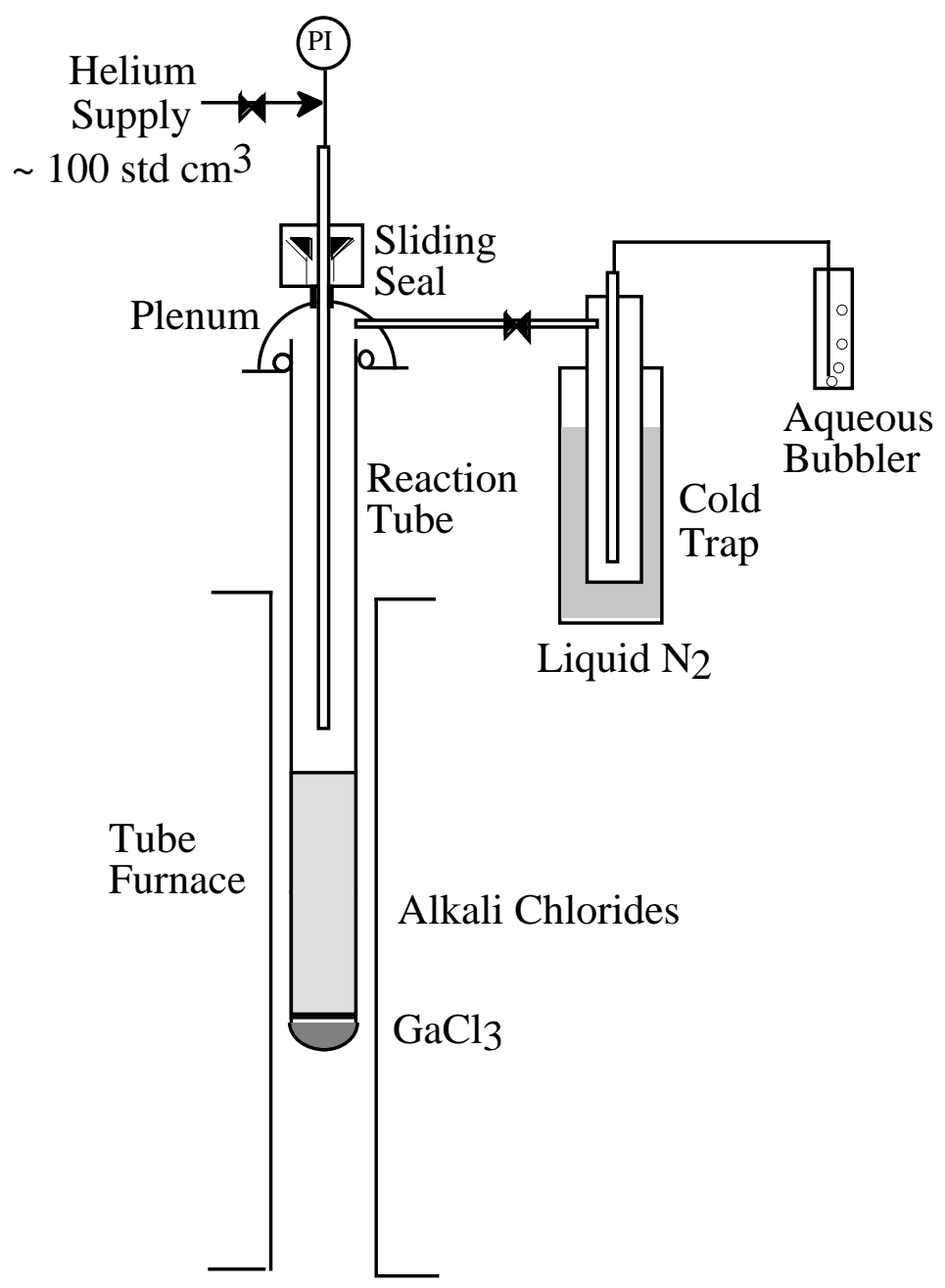

Fig. 2. First apparatus used for gallium volatility trials. 
The second apparatus consisted of a flanged quartz-and-glass enclosure for a 2-in.ID x 7.5-in.-long glassy carbon crucible (Sigradur GCD 400). The lower portion of the enclosure was a 3-in.-ID x 9-in.-long section of quartz tube with a flat bottom and with the "open end" joined to a 3-in.-ID x 5-in.-long section of Pyrex that terminated in a standard flanged joint with an O-ring seal. The upper portion of the enclosure was a standard Pyrex hemispherical plenum with Ace-Glass sidearm valves for sweeping the chamber volume and a central port for inserting a 1/4-in.-OD quartz sparge tube. The exhaust piping before the condenser and the plenum was completely heat-traced $\left(\sim 200^{\circ} \mathrm{C}\right)$ in order to concentrate the volatiles collection in the condenser. This apparatus is depicted in Fig. 3. A standard laboratory furnace and controller provided heating and temperature control, and the gas flows $\left(\mathrm{He}\right.$ and $\mathrm{Cl}_{2}$ ) were regulated by all-metal mass flow controllers.

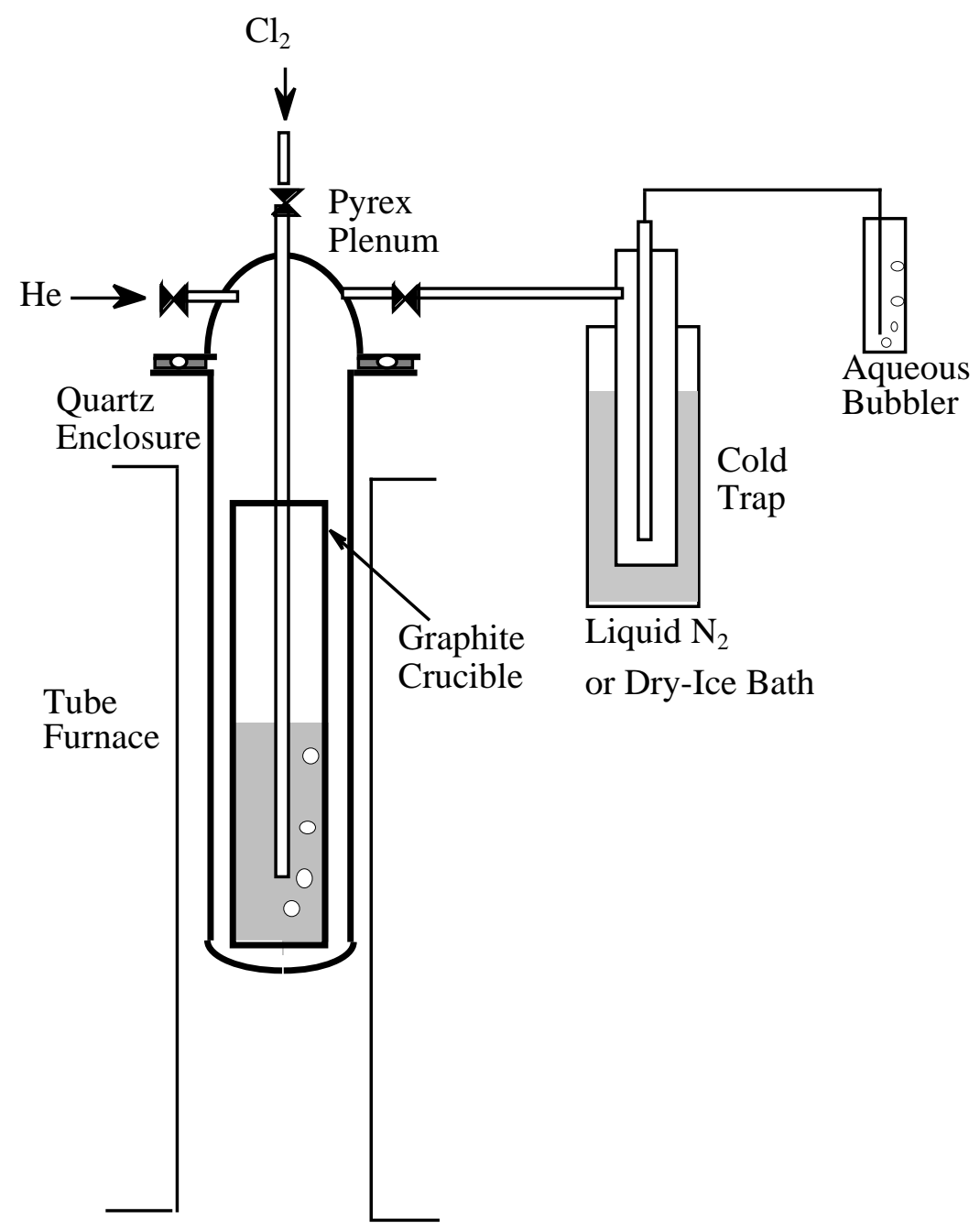

Fig. 3. Second apparatus used for gallium volatility trials. 
All of the trials involved material preparation, heating the salt mixture to the desired temperature under an inert cover gas, and sparging with a gas $\left(\mathrm{He}^{\text {or }} \mathrm{Cl}_{2}\right)$ to dissolve metals and/or drive off volatile species. For trials with gallium supplied as a salt $\left(\mathrm{GaCl}_{3}\right)$, the $\mathrm{GaCl}_{3}$ was always loaded first so it would be on the bottom of the chamber; the other salt constituents were added on top of the gallium salt. With this sequence, the $\mathrm{GaCl}_{3}$ could combine with the other salt constituents instead of simply being vaporized during the initial heating period. Careful observation and measurement of pressures during the initial heating indicated no loss of gallium as a vapor; rather it was clear that the gallium combined with the more basic salt constituents to form less volatile addition compounds. For those cases in which a graphite crucible was used and metal was dissolved with chlorine, the solvent salt (without cerium or gallium metal) was chlorinated first to remove the last vestiges of oxygen or moisture before the metal was added and dissolved by chlorination. When both cerium and gallium metal were used in one trial, the cerium was dissolved first and the gallium was added, dissolved, and volatilized in a second stage of the experiment.

In addition to temperature and gas-flow measurements, weights of various parts of the apparatus before and after treatment were measured to serve as gross indicators of chemical change. The most critical measurement for these experiments was the determination of the amount of gallium remaining in the salt after treatment. This determination was made by two types of Inductively Coupled Plasma Spectroscopy (ICP-S). For the initial results and for samples fairly concentrated in gallium, Optical Emission Spectroscopy (ICP-OES) was used in conjunction with appropriate gallium standards. For more precise analysis of dilute solutions of gallium (initially screened by ICP-OES), Mass Spectrometry (ICP-MS) was performed. Interference between cerium and gallium was eliminated by a special technique, developed by the ORNL Chemical and Analytical Sciences Division, that is described in Appendix A.

\section{RESULTS AND RECOMMENDATIONS}

This section includes an estimate of the free chloride content of our various trial salts, documentation of the conditions of the experimental trials (temperatures, flows, and 
duration), and estimates of the gallium removed from the salt based on weight changes and elemental analysis. The Lewis acidities of the various trial salts were calculated according to Eq. (1) and estimates of the cation coordination number. These coordination demands were based on data found in literature references or estimates from the evidence of compound formation in relevant phase diagrams. The estimates of Lewis acidity (i.e., free chloride content) should only be considered approximate because the coordination estimates do not account for all of the competition between the various species (especially the relative coordination strengths).

A detailed example of this type of estimate of free chloride content for the salt used in the AIDA/MOX study [2] is provided in Table 2. It is clear that the AIDA/MOX salt contains a significant excess of uncomplexed chloride and thus is basic in character. Both the composition and the Lewis-acid character of our trial salts are described in Table 3. The compositions that were selected represent a wide range of Lewis-acid behavior. The basis for the coordination demand estimates is described in Appendix B.

Detailed information on the conditions of experimental trials 2-4 is provided in Figs. 4-6, respectively. These figures document the temperature and gas-flow history of the experiments. The temperature overshoot in Fig. 4 did not appear to affect the gallium removal. For this trial (trial 2), no gallium was observed in the condenser until after the sparge had been started, and the collection of gallium was regular and gradual until it ceased at the end of the trial. For the last two trials, a helium sweep flow of $10 \mathrm{std} \mathrm{L} / \mathrm{h}$ was used in addition to the chlorine gas sparge to speed and complete the trapping of gallium chloride in the downstream condenser. The nominal experimental conditions and gallium removal results for the trial salts and the AIDA/MOX salt are compiled in Table 4. The gallium removals listed in this table are based on elemental analysis of the salt after the experiment.

A comparison of the results of this study compared with those from previous work [2, 6] in Table 4 shows the effects of Lewis acidity. The very basic salt mixture (trial 1) exhibited essentially no removal of gallium by volatility, while the acidic salt mixtures (trials 2-4) demonstrated considerable gallium removal-greater than that observed for the basic salt mixture of a previous study. The results are not directly comparable because of differences in temperatures and treatment times from trial to trial, but it is clear that increasing the Lewis 
acidity of the salt solution causes more gallium to be removed. Our last trial was conducted for an extended period to prove that the amount of gallium remaining in the salt could be reduced to very low levels in highly acidic solutions. Less than $0.01 \%$ of the initial charge of gallium was found in the salt after this experiment. Although extended treatment was applied during this trial, only slightly more chlorine was used than in the previous study. No visible amount of gallium was removed during the final $2 \mathrm{~h}$.

The significance of these results is that it may be possible to remove gallium more completely and easily if a more acidic salt system is used. Potential improvements afforded by a judicious choice of the salt composition include lower operation temperatures, shorter removal times, and more complete gallium removals. The simplest way to achieve a more acidic system is to dissolve additional plutonium. Other constituents could be added to the salt to make it more acidic, but their benefits must be weighed against the complications they might introduce (e.g., possible coprecipitation with plutonium in subsequent operations). Such findings suggest that the sensitivity of gallium removal to reasonable variations in the salt composition should be investigated further. 
Table 2. Estimate of free chloride content of the AIDA/MOX salt [2]

\begin{tabular}{|c|c|c|c|c|c|}
\hline Component & $\begin{array}{l}\text { Concentration } \\
\text { (wt \%) }\end{array}$ & Concentration (mol \%) & $\begin{array}{c}\text { Cation oxidation } \\
\text { number }\end{array}$ & $\begin{array}{c}\text { Cation } \\
\text { coordination } \\
\text { number }\end{array}$ & $\begin{array}{c}\text { Free chloride } \\
\text { balance }(\text { mol \%) }\end{array}$ \\
\hline $\mathrm{NaCl}$ & 24.2 & 43.3 & 1 & 0 & +43.3 \\
\hline $\mathrm{KCl}$ & 30.8 & 43.3 & 1 & 0 & +43.3 \\
\hline $\mathrm{GaCl}_{3}$ & 3.5 & 2.0 & 3 & 4 & $-(2.0)$ \\
\hline \multirow[t]{2}{*}{$\mathrm{PuCl}_{3}$} & 41.5 & 11.4 & 3 & 6 & $-(34.2)$ \\
\hline & & & & & Net $=+50.4$ \\
\hline
\end{tabular}


Table 3. Estimates of free chloride contents of experimental salt mixtures

\begin{tabular}{|c|c|c|c|c|c|}
\hline Reagent & $\begin{array}{l}\text { Reagent weight } \\
\text { (g) }\end{array}$ & $\begin{array}{l}\text { Concentration } \\
(\mathrm{mol} \%)\end{array}$ & $\begin{array}{c}\text { Cation oxidation } \\
\text { number }\end{array}$ & $\begin{array}{l}\text { Cation } \\
\text { coord. number }\end{array}$ & $\begin{array}{l}\text { Free chloride balance } \\
\qquad(\mathrm{mol} \%)\end{array}$ \\
\hline \multicolumn{6}{|c|}{ Trial 1 - Very basic salt mixture } \\
\hline $\mathrm{NaCl}$ & 11.78 & 34.0 & 1 & 0 & +34.0 \\
\hline $\mathrm{CsCl}$ & 63.15 & 63.3 & 1 & 0 & +63.3 \\
\hline \multirow[t]{2}{*}{$\mathrm{GaCl}_{3}$} & 2.85 & 2.7 & 3 & 4 & $-(2.7)$ \\
\hline & & & & \multicolumn{2}{|c|}{ Net $=+94.6$} \\
\hline \multicolumn{6}{|c|}{ Trial 2 -Acidic salt mixture } \\
\hline $\mathrm{CsCl}$ & 33.3 & 28.8 & 1 & 0 & +28.8 \\
\hline $\mathrm{MgCl}_{2}$ & 45.2 & 69.2 & 2 & 4 & $-(138.4)$ \\
\hline \multirow[t]{2}{*}{$\mathrm{GaCl}_{3}$} & 2.4 & 2.0 & 3 & 4 & $-(2.0)$ \\
\hline & & & & \multicolumn{2}{|c|}{ Net $=-\mathbf{1 1 1 . 6}$} \\
\hline \multicolumn{6}{|c|}{ Trial 3 - Acidic salt mixture (Ga-metal addition) } \\
\hline $\mathrm{CsCl}$ & 43.2 & 36.2 & 1 & 0 & +36.2 \\
\hline $\mathrm{MgCl}_{2}$ & 40.0 & 59.3 & 2 & 4 & $-(118.6)$ \\
\hline \multirow[t]{2}{*}{$\mathrm{Ga}$} & 2.2 & 4.5 & 3 & 4 & $-(4.5)$ \\
\hline & & & & \multicolumn{2}{|c|}{ Net $=-86.9$} \\
\hline \multicolumn{6}{|c|}{ Trial 4-Acidic salt mixture (Ce, Ga-metal additions) } \\
\hline $\mathrm{NaCl}$ & 9.5 & 24.7 & 0 & 1 & +24.7 \\
\hline $\mathrm{KCl}$ & 12.0 & 24.5 & 0 & 1 & +24.5 \\
\hline $\mathrm{CeCl}_{3}$ & 31.9 & \multirow{2}{*}{48.5} & \multirow{2}{*}{3} & \multirow{2}{*}{6} & \multirow{2}{*}{$-(145.5)$} \\
\hline $\mathrm{Ce}$ & 26.6 & & & & \\
\hline \multirow[t]{2}{*}{$\mathrm{Ga}$} & 1.0 & 2.3 & 3 & 4 & $-(4.5)$ \\
\hline & & & & \multicolumn{2}{|c|}{ Net $=-\mathbf{1 0 0 . 8}$} \\
\hline
\end{tabular}


Table 4. Experimental conditions and results

\begin{tabular}{|c|c|c|c|c|c|c|c|}
\hline \multirow{2}{*}{$\begin{array}{l}\text { Salt composition } \\
(\mathrm{mol} \mathrm{\% )})\end{array}$} & \multirow{2}{*}{$\begin{array}{c}\text { Average } \\
\text { temperature } \\
\left({ }^{\circ} \mathrm{C}\right) \\
\end{array}$} & \multirow{2}{*}{$\begin{array}{c}\text { Duration } \\
(\mathrm{h})\end{array}$} & \multicolumn{2}{|c|}{$\begin{array}{l}\text { Average sparge flow } \\
(\text { std L/h) }\end{array}$} & \multirow{2}{*}{$\begin{array}{l}\text { Crucible and } \\
\text { salt weight loss } \\
(\mathrm{g})\end{array}$} & \multirow{2}{*}{$\begin{array}{l}\text { Condenser } \\
\text { weight gain } \\
\text { (g) }\end{array}$} & \multirow{2}{*}{$\begin{array}{l}\text { Removal of } \\
\text { gallium }\end{array}$} \\
\hline & & & $\mathrm{Cl}_{2}$ & $\mathrm{He}$ & & & \\
\hline \multicolumn{8}{|c|}{ This study } \\
\hline $\begin{array}{c}\mathrm{NaCl}-\mathrm{CsCl}-\mathrm{GaCl}_{3} \\
(34-63-3 \%)\end{array}$ & 550 & 1 & 0 & 6 & - & - & $2 \%(\mathrm{OES})$ \\
\hline $\begin{array}{c}\mathrm{CsCl}-\mathrm{MgCl}_{2}-\mathrm{GaCl}_{3} \\
(29-69-2 \%)\end{array}$ & 575 & 1 & 0 & 4 & 2.4 & 2.4 & $\begin{array}{l}95 \%(\mathrm{MS}) \\
94 \%(\mathrm{OES})\end{array}$ \\
\hline $\begin{array}{c}\mathrm{CsCl}-\mathrm{MgCl}_{2}-\mathrm{GaCl}_{3} \\
(36.2-59.3-4.5 \%)\end{array}$ & 600 & 3 & 1 & 0 & - & 4.1 & $\begin{array}{l}89 \%(\mathrm{MS}) \\
92 \%(\mathrm{OES})\end{array}$ \\
\hline $\begin{array}{l}\mathrm{NaCl}-\mathrm{KCl}-\mathrm{CeCl}_{3}-\mathrm{GaCl}_{3} \\
(24.7-24.5-48.5-2.3 \%)\end{array}$ & 725 & 5 & 2 & 0 & 2.0 & 2.8 & $99.99 \%(\mathrm{MS})$ \\
\hline \multicolumn{8}{|c|}{ Previous study $[2,6]$} \\
\hline $\begin{array}{c}\mathrm{NaCl}-\mathrm{KCl}-\mathrm{PuCl}_{3}-\mathrm{GaCl}_{3} \\
(43.3-43.3-11.4-2.0 \%)\end{array}$ & 720 & 1 & $5-10$ & 0 & - & - & $\sim 85 \%$ \\
\hline
\end{tabular}




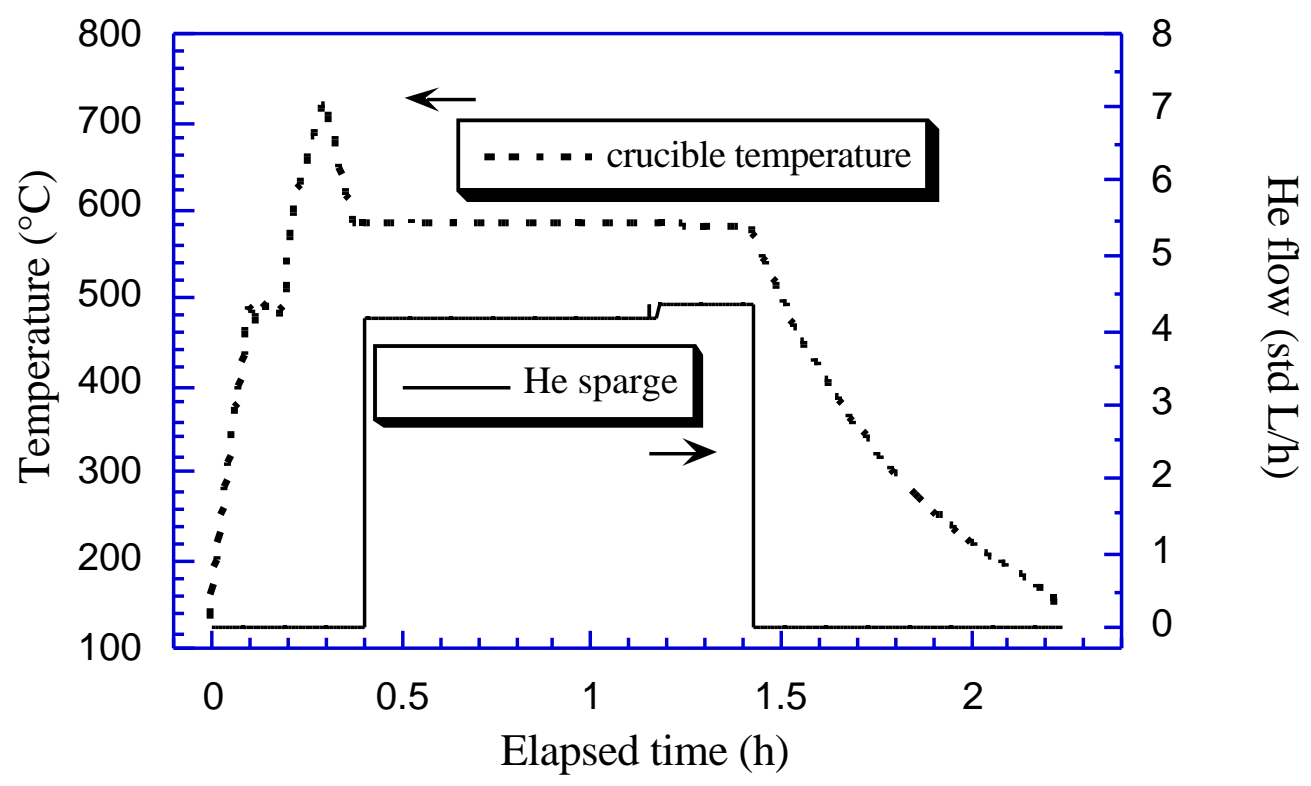

Fig. 4. Temperature and flow history for trial $2\left(\mathrm{CsCl}-\mathrm{MgCl}_{2}-\mathrm{GaCl}_{3}, 29-69-2 \mathrm{~mol} \%\right)$.

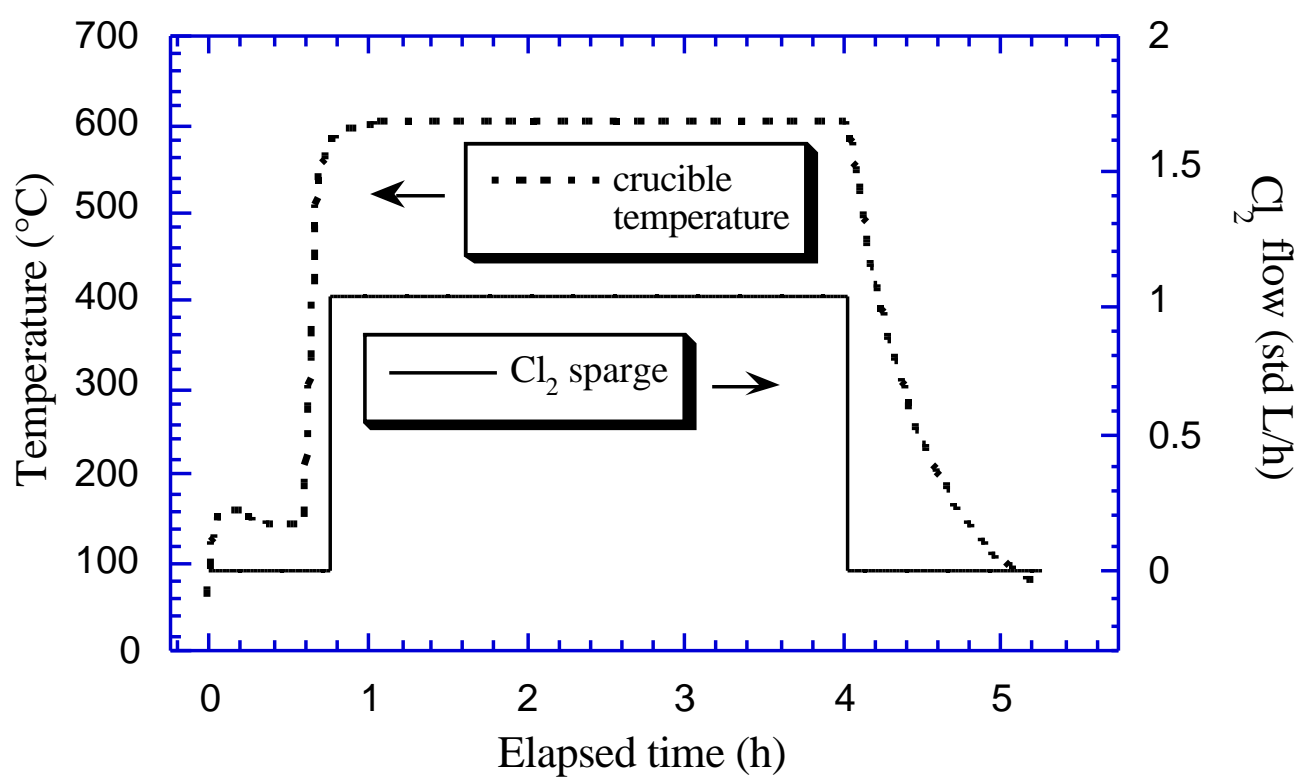

Fig. 5. Temperature and flow history for trial $3\left(\mathrm{CsCl}-\mathrm{MgCl}_{2}-\mathrm{GaCl}_{3}, 36.2-59.3-4.5 \mathrm{~mol} \%\right)$. 


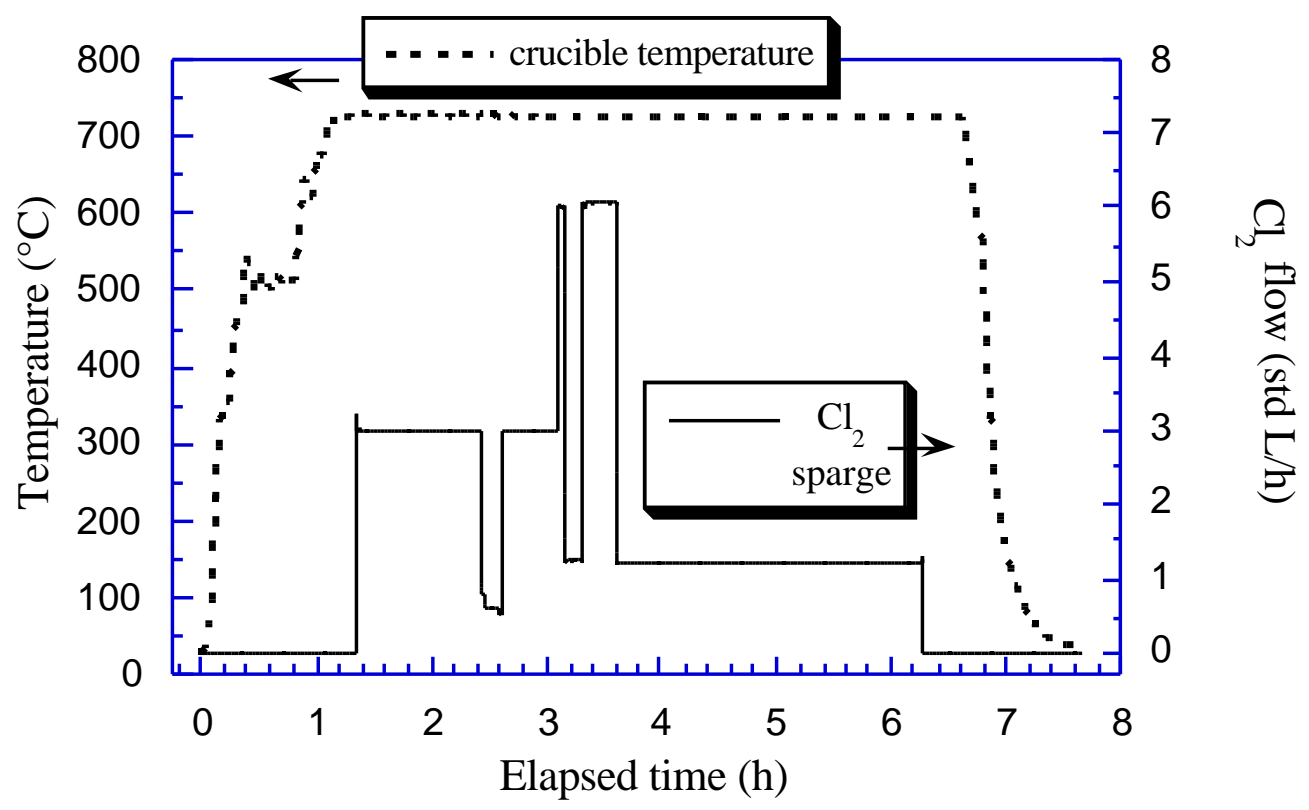

Fig. 6. Temperature and flow history for trial 4 ( $\left.\mathrm{NaCl}-\mathrm{KCl}-\mathrm{CeCl}_{3}-\mathrm{GaCl}_{3}, 24.7-24.5-48.5-2.3 \mathrm{~mol} \%\right)$. 


\section{REFERENCES}

1. E. D. Collins et al., Measurement of Achievable Plutonium Decontamination from Gallium by Means of Purex Solvent Extraction, ORNL/TM-1999/312, Oak Ridge National Laboratory, January 2000.

3. A. G. Osipenko and J. Laquement, et al., "Conversion of Weapon-Grade Plutonium into Nuclear MOX Fuel by Pyrochemical Methods," Molten Salt Forum 5-6, 533 (Proceedings of the 5th International Symposium on Molten Salt Chemistry and Technology, Dresden, August 1997), TransTech Publications, Switzerland, 1998.

4. W. R. Grimes et al., "Chemical Aspects of Molten Fluoride Reactors," pp. 152-56 in Progress in Nuclear Energy, Series IV - Volume 2: Technology, Engineering and Safety, Pergamon Press, New York, 1960.

5. H. Linga et al., "Vapor-Pressures of Molten Alkali Chloride-Aluminum Chloride Mixtures," Ber. Bunsen Phys. Chem. 82, 568 (1978).

6. J. T. Viola et al., "Vapor Pressure of Aluminum Chloride Systems: 3. Vapor Pressure of Aluminum Chloride-Sodium Chloride Melts," J. Chem. Eng. Data 23, 122 (1978).

7. J. Laquement, French Atomic Energy Commission, CEA/DCC, private communications with E. D. Collins on August 18, 1998, and L. M. Toth on March 9, 2000 . 
Appendix A

\section{GALLIUM ANALYSIS}




\section{Appendix A. Gallium Analysis}

Determination of the amount of gallium remaining in the salt after treatment was done by dissolving the chloride salt completely in dilute nitric acid and then performing elemental analysis. This analysis was performed using an Inductively Coupled Plasma (ICP) device coupled to either an Optical Emission Spectrometer (ICP-OES) or a Mass Spectrometer (ICP-MS). In the higher concentration ranges ( $>50 \mathrm{ppm}$ gallium), the ICP-OES measurements were accurate to within $1 \%$ when calibration standards were also run. In the lower concentration ranges, the ICP-MS was much more sensitive. At the trace level of the final trial, the ICP-MS measurements were reported to be accurate to within $10 \%$. Extensive trace-level recalibration and matrix standards would be required to achieve higher accuracy at these low gallium concentrations. The following technique, developed by the Chemical and Analytical Sciences Division (CASD) of ORNL, was used to eliminate the interference between cerium and gallium. The ICP-MS analyses were performed by J. M. Giaquinto of the CASD.

An EiChrom Industries TruSep resin column was used for separation of gallium in the presence of cerium. This technique was originally developed for gallium analysis in the presence of high cerium for irradiated MOX fuels. The TruSep resin is used mainly to separate the actinides, but it also has a strong affinity for the lanthanide elements in the $3+$ oxidation state in a concentrated nitric acid matrix ( $>3 M$ ). Gallium recoveries of greater than $90 \%$ were observed for low-level gallium-spikes in MOX fuel. Method blanks showed no gallium contamination.

Natural gallium has two analytical masses, 69 and 71. For the ICP-MS scans before separation, mass 71 had obvious an interference; and from previous experience it was clear that this interference was due to the high levels of cerium present. Mass 69 is not affected by cerium but mass 69.5 is. It was apparent from the mass 69 response that low levels of gallium were present in the samples; however, given the interference at mass 69.5, it was difficult to quantify the level of gallium before the separation treatment described above. Post-column analysis scans showed that cerium was effectively removed and the gallium mass peaks were clearly measured above background.

The following is a brief outline of how the samples were handled. 
1. Samples were filtered to remove trace graphite particulates.

2. Filtered portions were diluted 100 -fold using $4 M \mathrm{HNO}_{3}$.

3. Dilutions were passed through TruSep columns and the eluant collected.

4. A portion of the eluant was diluted an additional 5-fold using $2 \% \mathrm{HNO}_{3}$, and these dilutions were quantified for gallium.

The results of the analysis for the final trial after separation of the cerium are shown in the following table.

Table A.1. Gallium analysis results for trial 4

( $\left.\mathrm{NaCl}-\mathrm{KCl}-\mathrm{CeCl}_{3}-\mathrm{GaCl}_{3}, 24.7-24.5-48.5-2.3 \mathrm{~mol} \%\right)$

\begin{tabular}{lcccc}
\hline ORNL sample & $\begin{array}{c}\text { Sample } \\
\text { description }\end{array}$ & $\begin{array}{c}\text { Sample volume } \\
(\mathrm{mL})\end{array}$ & $\begin{array}{c}\text { Gallium } \\
\text { concentration } \\
(\mathrm{ppm})\end{array}$ & $\begin{array}{c}\text { Amount of } \\
\text { gallium (mg) }\end{array}$ \\
\hline $\begin{array}{l}\text { 000613-004 } \\
(\mathrm{GA01})\end{array}$ & Crucible wash & 121 & $0.255 \pm 0.026$ & 0.031 \\
$\begin{array}{l}\text { 000613-005 } \\
(\mathrm{GA02})\end{array}$ & Dissolved salt & 181 & $0.020 \pm 0.002$ & 0.0036 \\
\hline
\end{tabular}


Appendix B

COORDINATION NUMBERS FOR SELECTED CATIONS 


\section{Appendix B. Coordination Numbers for Selected Cations}

There are no readily available coordination data for magnesium and cerium molten chloride mixtures. However, a good estimate of these coordination numbers can be obtained by examining the phase diagram and crystal structure data $[1,2]$. When multiple coordination compounds are evident from the phase diagram, the entropy effect on melting often tends to decrease the coordination number from its highest value. An example that has been well documented is that for U(IV). Mixed fluoride compounds of 7,8 , and 9 coordination have been found in phase-diagram/crystal-structure studies, but only an equilibrium between 7- and 8-coordinated species has been observed in melts [3].

In the case of $\mathrm{MgCl}_{2}$ (Figs. 1231, 5647 and 5661 in [1] with $\mathrm{CsCl}, \mathrm{KCl}$, and $\mathrm{NaCl}$, respectively), 3:1, 2:1, 1:1, and 1:3 compounds for $\mathrm{CsCl}: \mathrm{MgCl}_{2}$ are observed; however, for $\mathrm{KCl}: \mathrm{MgCl}_{2}$ and $\mathrm{NaCl}: \mathrm{MgCl}_{2}$, only the $2: 1$ and $1: 1$ compounds are found. It is assumed that the 3:1 compound, that is, the one with five chloride ions around the $\mathrm{Mg}(\mathrm{II})$ ion, is not stable at high (molten salt) temperatures. Furthermore, since the crystal structures indicate that the 1:1 compound involves a shared tetrahedral arrangement of chloride ions about the $\mathrm{Mg}$ (II) ion whereas the 2:1 compound is an unshared arrangement of chloride ions, the coordination number of $\mathrm{Mg}(\mathrm{II})$ in chloride melts should ordinarily be 4, whether these are shared or not.

In the case of $\mathrm{CeCl}_{3}$ (Figs 1235 and 1275 of [1] ), with $\mathrm{CsCl}, \mathrm{KCl}$, respectively, 3:1 MCl: $\mathrm{CeCl}_{3}$ compounds exist in both salt mixtures plus a 2:1 compound in the $\mathrm{KCl}$ binary mixture. Since a coordination number of 6 for the $\mathrm{Ce}(\mathrm{III})$ ion is found crystallographically, with the 2:1 compound probably involving a shared chloride ion, the coordination number of $\mathrm{Ce}(\mathrm{III})$ in chloride melts should be 6 .

For $\mathrm{Ga}(\mathrm{III})$, a chloride coordination number of 4 is predicted by comparison with its analog $\mathrm{Al}(\mathrm{III})$, which is known to be 4-coordinate. Likewise, $\mathrm{Pu}(\mathrm{III})$ is similar to $\mathrm{Ce}(\mathrm{III})$ and would therefore be 6-coordinate in chloride melts.

\section{References for Appendix B}

1. M. R. Reser, ed., E. M. Levin, C. R. Robbins, and H. F. McMurdie, Phase Diagrams for Ceramists, Am. Ceram. Soc., 1964.

2. R. W. G. Wyckoff, Crystal Structures, 2nd ed., Interscience, John Wiley and Sons, New York, 1964.

3. L. M. Toth, "Coordination Effects on the Spectrum of Uranium(IV) in Molten Fluorides," J. Phys. Chem. 75, 631 (1971) . 


\section{INTERNAL DISTRIBUTION}

1. B. B. Bevard

2. E. D. Collins

3. B. S. Cowell

4. S. Dai

5. G. D. Del Cul

6. L. K. Felker

7. J. M. Giaquinto

8. S. R. Greene

9. A. S. Icenhour

10. R. T. Jubin

11. J. M. Keller
12. L. E. McNeese

13. D. L. Moses

14. D. W. Simmons

15. D. J. Spellman

16. L. M. Toth, consultant

17. L. D. Trowbridge

18. R. M. Wham

19-23. D. F. Williams

24. Central Research Library

25. ORNL Laboratory Records-RC 26-27.ORNL Laboratory Records-OSTI

\section{EXTERNAL DISTRIBUTION}

28. K. Aratani, Group Leader, Surplus Weapons Plutonium Disposition Group, Japan Nuclear Cycle Development Institute, 4-49, Muramatsu Tokai-mura, Naka-gun, Ibaraki, T 319-1184, Japan.

29. J. F. Baker, U.S. DOE, NN-63, 1000 Independence Avenue SW, Washington, DC 20585.

30. P. Brossard, Adjoint au Chef du SPHA, French Atomic Energy Commission (CEA/DCC/DRRV/SPHA), CEA-ValRhô, B.P. 171, 30207 Bagnols Sur Cèze CEDEX.

31. A. V. Bychkov, Head of Fuel Cycle Department, State Scientific Center of the Russian Federation: "Research Institute of Atomic Reactors" (RIAR), ChemicalTechnological Division , 433510, Dimtrovgrad-10, Ulyanovsk region, Russia.

32. A. Caponiti, U.S. DOE, NN-63, 1000 Independence Avenue SW, Washington, DC 20585.

33. C. F. Mason, Los Alamos National Laboratory, P.O. Box 1663, MS-E530, Los Alamos, New Mexico 87545.

34. F. G. Reshetnikov, Advisor and Professor, Academician Russian Academy of Sciences, A. A. Bochvar All-Russia Institute of Inorganic Materials (VNIINM); Rogova str. 5; Moscow 123060 P.O.B. 369; Russia.

35. N. B. Sokolov, Deputy Director of Department: Fuel Design, Fuel Technology, and Reactor Core Materials, A. A. Bochvar All-Russia Institute of Inorganic Materials (VNIINM), Rogova str. 5; 123060, Moscow, Russia. 
36. S. Thomas, U.S. DOE, NN-63, 1000 Independence Avenue SW, Washington, DC 20585.

37. A. Yamato, Executive Director, Japan Nuclear Cycle Development Institute, 4-49, Muramatsu Tokai-mura; Naka-gun, Ibaraki; T 319-1184, Japan.

38. S. J. Zygmunt, Los Alamos National Laboratory, P.O. Box 1663, MS-E510, Los Alamos, New Mexico 87545. 